\title{
A FoRMAÇÃo CONTINUAda de LICENCIAdos EM Física COM O USO do Planetário para O ENSINo DE Astronomia
}

\author{
CONTINUING EDUCATION OF PHYSICISTS WITH THE USE OF THE \\ PLANETARIUM FOR THE TEACHING OF ASTRONOMY
}

DOI: http://dx.doi.org/10.23926/RPD.2526-2149.2019.v4.n1.p196-211.id373

\author{
José Ademir \\ Damasceno Júnior \\ Mestre em Ensino de \\ Ciências e Matemática \\ (IFCE) \\ profademir7@gmail.com

\section{Mairton Cavalcante Romeu} \\ Doutorando em Astrofísica \\ (UFC) \\ mairtoncavalcante@gmail.co \\ $\underline{m}$
}

\begin{abstract}
Resumo: Esta pesquisa procurou investigar sobre o uso do Planetário como recurso teórico e metodológico na formação continuada de professores de Física. Apesar de serem encontrados facilmente na literatura nacional e internacional trabalhos que reconhecem as contribuições da Astronomia na formação de professores, esta disciplina ainda é pouco ofertada no Brasil pelos cursos de licenciatura em Física. Levantou-se o questionamento de como o Planetário pode contribuir na formação continuada de licenciados em Física. Portanto, este trabalho teve como objetivo geral realizar uma análise sobre a relevância do recurso "Planetário" na prática docente de licenciados em Física, tomando por base resultados de pesquisas anteriores descritos em artigos, dissertações e teses, no período de 2006 a 2016. Os resultados elucidam diversas evidências que o uso do Planetário poderá contribuir significativamente na formação continuada de professores de Física, devido ao interesse que desperta nas pessoas, a pré-disposição do indivíduo em estudar Astronomia; e por possuir sessões adequadas ao nível de ensino e etapa escolar dos alunos. Neste trabalho, conclui-se que, oportunizando aos professores uma formação continuada, através de uma fundamentação de abordagem teórica e metodológica com o uso do recurso Planetário, será possível promover nesses profissionais uma mudança de postura em sua prática pedagógica.
\end{abstract}

Palavras-chave: Ensino de Astronomia; Formação continuada; Planetário como recurso metodológico.

\begin{abstract}
This research sought to investigate the use of the Planetarium as a theoretical and methodological resource in the continuing training of physics teachers. Although it is easy to find in the national and international literature works that recognize the contributions of astronomy to teacher training, this discipline is still little offered in Brazil by undergraduate courses in Physics. The question has been raised as to how the Planetarium can contribute to the continuing education of physicists. The objective of this work was to analyze the relevance of the "Planetary" resource in the teaching practice of physicists, based on the results of previous researches described in articles, dissertations and theses, from 2006 to 2016. The results elucidate diverse evidences that the use of the Planetarium can contribute significantly in the continuous formation of Physics teachers, due to the interest that arouses in the people, the pre-disposition of the individual in studying Astronomy; and for having adequate sessions at the level of teaching and scholastic stage of the students. In this work, it is concluded that, giving teachers continuous training, through a theoretical and methodological approach with the use of the Planetarium resource, it will be possible to promote in these professionals a change of attitude in their pedagogical practice.
\end{abstract}

Keywords: Astronomy Teaching; Continuing training; Planetary as a methodological resource. 


\section{INTRODUÇÃO}

Percebe-se que a Astronomia, desde o advento da humanidade, provoca o fascínio nas pessoas, seja em crianças ou nos adultos. Os egípcios, dentre outras civilizações antigas, já faziam desenhos do céu em tumbas. Por sua vez, os nativos americanos, representavam alguns corpos celestes através de desenhos nas paredes das cavernas e penhascos (THORNBURGH, 2017).

Os povos da Grécia antiga ficaram conhecidos por construírem globos que retratavam constelações e movimentos planetários (THORNBURGH, 2017). Acredita-se que justamente o fascínio pela Astronomia, associada às diversas áreas do conhecimento, tenha influenciado o desenvolvimento da Física, Química, Biologia, História, Geografia, Filosofia, Sociologia, das navegações, da poesia, da música, da literatura, dentre outras (BARAI et al., 2016).

Baseado no fato de que a Astronomia, até nos dias atuais, encanta públicos de várias idades, a demanda por instrumentos que atendam à curiosidade dos indivíduos sobre conceitos a ela voltados e até mesmo que contribuam para os processos de ensino e aprendizagem científica se revela cada vez mais imprescindível (ROMANZINI, 2011).

Segundo Romanzini (2011), para atender às inquietações da humanidade, especialmente para o processo de ensino e aprendizado, encontram-se disponíveis inúmeros recursos, tais como: softwares desenvolvidos para a confecção de cartas celestes ou para a representação dos movimentos planetários, livros e documentários de divulgação científica, além de ambientes que proporcionam uma série de experiências relacionadas a este campo do saber.

Quanto às iniciativas institucionais, Romanzini (2011) destaca que os Planetários são ambientes de imersão, através do qual se pode ter uma reprodução da esfera celeste por meio de um equipamento óptico com o potencial de projetar em um teto abobadado as estrelas em suas posições aparentes, assim como outros corpos celestes.

Portanto, verifica-se que por meio das revoluções tecnológicas, a humanidade adquiriu mais conhecimento em diversas áreas, especialmente sobre o espaço sideral. Nesse contexto, surge esse modelo de planetário moderno, que possuem sofisticados projetores que utilizam dados científicos, ao mesmo tempo que possibilitam uma visão do universo (THORNBURGH, 2017).

Barai et al. (2016) enaltece o caráter interdisciplinar da Astronomia, podendo ser relacionada ao estudo dos conceitos da Física, Química, Geografia, dentre outras áreas do saber, fator este que propicia ao aluno uma oportunidade de desenvolvimento maior do que vários outros ramos da ciência e nas mais variadas habilidades. 
Nesse sentido, os Planetários também proporcionam uma abordagem inter e multidisciplinar de diversos conceitos, devido ao caráter abrangente da Astronomia, que permite que vários campos do saber sejam explorados em uma única atividade, epistemológica e didaticamente planejada (BISHOP, 1979; OTHMAN, 1991; BARRIO, 2002; SALVI; BATISTA, 2006; MARTINS, 2009).

Contudo, Plummer (2006), através da investigação que realizou em seu trabalho, percebeu que concepções alternativas verificadas em crianças e adolescentes estão relacionadas ao fato destas não estarem recebendo instruções precisas de seus pais e de outros adultos (por exemplo, dos professores) com quem elas convivem.

Acredita-se que as lacunas apresentadas pelos professores de Física para o ensino de Astronomia decorram por diversos motivos, como, por exemplo, da organização curricular dos cursos, que não distribui a carga horária de forma equilibrada, existindo uma forte discrepância entre a carga horária destinada para a formação específica e quanto à destinada para a formação geral (DARROZ; SANTOS, 2013).

Este trabalho teve como objetivo geral realizar uma análise acerca da relevância do recurso "Planetário" na formação continuada de licenciados em Física para o ensino de Astronomia.

\section{Metodologia}

Este trabalho consiste num levantamento bibliográfico sobre formação de professores de Física, e uso do Planetário como recurso teórico e metodológico, tomando por base os autores da área, documentos oficiais nacionais, e resultados de pesquisas anteriores descritos em artigos, dissertações e teses, no período de 2006 a 2016, por meio de consultas a plataformas digitais. A qualidade das produções científicas que foram analisadas foi verificada através da pertinência dos resumos dos trabalhos em relação ao objeto de estudo desta pesquisa. Foi avaliado também o Qualis dos periódicos das revistas, nas quais estavam inseridos os artigos. Conforme Gil (2008), uma pesquisa bibliográfica é desenvolvida com base em material já elaborado, constituído principalmente de livros e artigos científicos. 


\title{
3 Discursos TeÓricos
}

\subsection{ENSINO DE CIÊNCIAS}

Na literatura da área de ensino de Ciências são encontradas inúmeras razões associadas a uma deficiente formação de professores. Gonzatti (2008, p. 11) aponta que:

\begin{abstract}
Os professores das séries iniciais do ensino fundamental geralmente têm uma formação deficiente em áreas como a física. Isso ocorre por diferentes razões. Uma das principais, a nosso ver, é a tendência atual dos currículos dos cursos de formação de professores de equiparar as cargas horárias de formação geral com as de formação pedagógica e de práticas curriculares. Em decorrência disso, a carga horária total destinada ao aprendizado do conteúdo de física, assim como em outras áreas, fica aquém do desejável.
\end{abstract}

A autora indica ainda que "Os professores deste nível se sentem despreparados conceitual e metodologicamente para desenvolver tópicos de ciências, especialmente aqueles relacionados à física" (GONZATTI, 2008, p. 12).

Outra dificuldade verificada refere-se ao insuficiente número de cursos de Física no Brasil que oferecem a disciplina de Astronomia, bem como uma desigual oferta/distribuição dos mesmos entre as diferentes regiões do país.

Quadro 1 - Síntese do número de cursos e alunos distribuídos por região, pelo tipo de instituição e pela presença da disciplina de Astronomia

\begin{tabular}{|c|c|c|c|c|c|c|c|}
\hline & \multicolumn{2}{|c|}{ Disciplina obrigatória } & \multicolumn{2}{|c|}{ Disciplina optativa/eletiva } & \multicolumn{2}{|c|}{$\begin{array}{l}\text { Sem disciplina de } \\
\text { Astronomia }\end{array}$} \\
\hline & & Pública & Particular & Pública & Particular & Pública & Particular \\
\hline \multirow[t]{2}{*}{ Sul } & cursos & 3 & 4 & 9 & 0 & 2 & 2 \\
\hline & alunos & 194 & 44 & 141 & 0 & 20 & 5 \\
\hline \multirow[t]{2}{*}{ Sudeste } & cursos & 5 & 2 & 15 & 0 & 7 & 18 \\
\hline & alunos & 77 & 17 & 279 & 0 & 109 & 217 \\
\hline \multirow{2}{*}{$\begin{array}{l}\text { Centro } \\
\text { Oeste }\end{array}$} & cursos & 1 & 2 & 6 & 0 & 4 & 0 \\
\hline & alunos & 32 & 51 & 104 & 0 & 144 & 0 \\
\hline \multirow[t]{2}{*}{ Nordeste } & cursos & 3 & 0 & 10 & 0 & 22 & 2 \\
\hline & alunos & 128 & 0 & 137 & 0 & 455 & 18 \\
\hline \multirow[t]{2}{*}{ Norte } & cursos & 0 & 0 & 2 & 0 & 12 & 1 \\
\hline & alunos & 128 & 0 & 137 & 0 & 455 & 18 \\
\hline
\end{tabular}

Fonte: Roberto Júnior, Reis e Germinaro (2014, p. 93)

Nota-se, no Quadro 1, que o número de cursos com a disciplina de Astronomia tem crescido no Brasil, porém, percebe-se que sua oferta ainda é bem maior como uma disciplina optativa/eletiva em todas as regiões.

Comprova-se que o número de cursos sem a disciplina de Astronomia também é mais expressivo em todas as regiões, exceto na região Sul. Observa-se também que as regiões Centro Oeste e Nordeste oferecem um menor número de cursos onde a disciplina de Astronomia é obrigatória. 
Percebe-se também que a região Norte não oferece nenhum curso onde a disciplina de Astronomia é obrigatória. Acredita-se que essa desigual oferta da disciplina de Astronomia verificada nas regiões brasileiras representa um entrave para o desenvolvimento dessa ciência em nosso país. Defende-se que uma distribuição mais equitativa pelo território brasileiro de cursos que ofereçam essa área do conhecimento, sobretudo como disciplina obrigatória, poderá contribuir de forma mais significativa para o avanço do ensino de Astronomia.

É notório e preocupante o número de cursos de Física que possuem a disciplina de Astronomia apenas como optativa/eletiva.

Há $70(53 \%)$ cursos que não possuem nenhuma disciplina de Astronomia na sua estrutura curricular e 42 (32\%) que possuem apenas disciplinas optativas/eletivas. $\mathrm{O}$ significado desses dados é que a maioria absoluta dos cursos de Licenciatura em Física não possui na sua estrutura curricular a disciplina obrigatória de Astronomia (ROBERTO JUNIOR; REIS; GERMINARO, 2014, p. 94).

É alarmante a quantidade de alunos de Licenciatura em Física, sobretudo nas regiões Norte e Nordeste, que conclui o curso sem ter estudado os conceitos dessa relevante ciência.

Um total de 1207 alunos que concluíram o curso sem terem contato com o conteúdo dessa ciência, sendo que 59\% deles estão nas regiões Norte e Nordeste. Para 684 deles há a possibilidade de terem feito alguma disciplina com esse conteúdo e para apenas 368 é possível afirmar que esses futuros professores de Física tiveram aulas de Astronomia. Para $84 \%$ dos estudantes de Licenciatura em Física há grandes possibilidades deles se formarem sem uma disciplina de Astronomia na graduação (ROBERTO JUNIOR; REIS; GERMINARO, 2014, p. 94).

Nesse sentido, apesar de muitos esforços, tais como: legislação vigente (por exemplo, PCNEM), diferentes publicações científicas (artigos, dissertações e teses), relevantes encontros nacionais (por exemplo, Simpósio Nacional de Educação em Astronomia - SNEA ${ }^{1}$ ), olimpíadas (Olimpíada Brasileira de Astronomia e Astronáutica - $\mathrm{OBA}^{2}$ ), dentre outros, as universidades brasileiras não se adequaram à necessidade que possui o país para promover melhorias no ensino de Astronomia.

[...] a distribuição da disciplina de Astronomia pelas regiões [...] verifica-se que no Norte, nenhum curso avaliado possui disciplina obrigatória com esse conteúdo na sua estrutura curricular. Em 13 dos 15 cursos não há sequer uma disciplina optativa/eletiva.

No Nordeste a situação é um pouco diferente, mas não muito melhor. Nessa região há 3 cursos com disciplinas obrigatórias, mas 24 dos 37 cursos não possuem essa

\footnotetext{
${ }^{1}$ O SNEA (Simpósio Nacional de Educação em Astronomia) foi idealizado em 2009, durante a Assembleia Geral da União Astronômica Internacional no Rio de Janeiro, para servir de fórum nacional para debate de ideias, apresentação de trabalhos e estruturação da educação em astronomia. O primeiro simpósio nacional ocorreu em 2011, no campus da Universidade Federal do Estado do Rio de Janeiro (UNIRIO). Disponível em: < https://sabastro.org.br/eventos/snea/>. Acesso em: 10 jun. 2018.

${ }^{2}$ Evento aberto à participação de escolas públicas ou privadas, urbanas ou rurais, para alunos do $1^{\circ}$ ano do ensino fundamental até alunos do último ano do ensino médio. Em 18/05/2018 ocorreu sua $21^{\mathrm{a}}$ edição. Disponível em: < http://www.oba.org.br/site/ >. Acesso em: 10 jun. 2018.
} 
disciplina. Nessas duas regiões quase todos os cursos e consequentemente alunos estão em instituições públicas (ROBERTO JUNIOR; REIS; GERMINARO, 2014, p. 95).

Todavia, as regiões Sudeste, Sul e Centro-Oeste, apresentam um quadro mais otimista no que se refere à obrigatoriedade da disciplina de Astronomia:

Entretanto, essa região possui o maior número de alunos (94) em cursos com disciplina obrigatória de Astronomia. As regiões Sul e Centro-Oeste se destacam por possuírem uma situação oposta à das outras, nelas a minoria dos cursos não tem disciplinas de Astronomia (ROBERTO JUNIOR; REIS; GERMINARO, 2014, p. 94).

Percebe-se que a UFRS favorece aos seus alunos um melhor estudo dos conceitos astronômicos, por meio de disciplinas de Astronomia obrigatórias, através de uma maior carga horária, e também por meio de uma ementa que contempla uma grande diversidade de assuntos. Nesse viés, é possível afirmar que a UFRS valoriza a relevância do estudo de Astronomia para a sociedade, proporcionando uma formação mais adequada aos seus estudantes.

[...] o curso da Universidade Federal do Rio Grande do Norte onde a ementa da disciplina possui, além do conteúdo padrão, o seguinte assunto: "o ensino de Astronomia nos níveis de escolaridade fundamental e médio, cuidados, métodos e atividades" (ROBERTO JUNIOR; REIS; GERMINARO, 2014, p. 94).

Interessante destacar que algumas universidades apresentam em suas ementas, na disciplina de Astronomia, uma abordagem diferenciada, que está além do conteúdo tradicional:

[...] na PUC do Rio Grande do Sul e na Universidade Estadual do Mato Grosso do Sul a ementa possui, além dos conteúdos tradicionais, o seguinte assunto: a "Astronomia como agente social de divulgação de ciências". Como pode ser observado nas ementas das disciplinas desses cursos, o ensino de Astronomia vai além do conteúdo tradicional. Esses cursos buscam estudar metodologias de ensino e divulgação dessa ciência no ensino fundamental e médio e também a investigação da sua relação com as outras ciências a tecnologia e a sociedade (ROBERTO JUNIOR; REIS; GERMINARO, 2014, p. 94).

Entende-se que ao possibilitarem que seus alunos estudem métodos de ensino, principalmente de forma contextualizada, essas universidades estarão contribuindo para que futuros professores não apresentem as mesmas limitações evidenciadas atualmente.

\subsection{Formação Continuada de Professores de Física (FCPF)}

Quanto à formação continuada de professores de Física (FCPF), felizmente, nos dias atuais, encontra-se na literatura uma concepção bem distinta daquela que reduz a mesma a treinamento, aperfeiçoamento, reciclagem e capacitação (SAUERWEIN; DELIZOICOV, 2009).

Marin (1995) explica que o termo reciclagem é inapropriado para ser utilizado com pessoas, sobretudo com profissionais da educação, pois o seu conceito está fortemente relacionado à reutilização/modificação de materiais, por exemplo, papéis, copos, garrafas, entre 
outros, objetos que podem ser modificados para outros fins, e, desse modo, divergente dos conceitos pedagógicos atuais.

Segundo Marin (1995), o termo reciclagem, ao ser utilizado com os profissionais da educação, terá como pressuposto que estes não possuem saberes/conhecimentos profissionais em sua ação docente. A autora esclarece que, dessa forma, estaríamos considerando que os profissionais da educação seriam como "tábula rasa", sem conhecimentos prévios.

Marin (1995) entende que cursos de aperfeiçoamento individual de curta duração apresentam subjacente uma concepção de carência conceitual e metodológica da prática docente, em que estes serão suficientes para suprir as necessidades dos professores. Por outro lado, formações docentes contínuas e coletivas caracterizam-se por estarem além da exigência reducionista de competências conceituais e metodológicas do professor, sendo amparadas através de um trabalho mais sistemático e permanente na vida profissional docente.

Uma concepção que pode ser facilmente verificada, com destaque no cenário da FCPF, denomina-se por concepção orgânica, sendo apontada como referência em inúmeros artigos de periódicos e publicações em congressos. A referida concepção caracteriza-se por:

[...] além de considerarem os diversos aspectos do ensino da Física, também levam em conta que as transformações das práticas docentes não ocorrem diretamente após a participação em cursos. Essa concepção considera outras variáveis relevantes na tarefa docente como, por exemplo, a organização da escola, a relevância que cada unidade escolar dá para a formação continuada e permanente do seu quadro docente, as dificuldades do professor na tarefa docente, a importância do conhecimento das concepções dos alunos no que diz respeito à Física, o conhecimento e a utilização de resultados da pesquisa em ensino de Física no planejamento das aulas, as concepções do professor, principalmente, sobre o papel da educação e do ensino de Física, entre outras (SAUERWEIN; DELIZOICOV, 2008, p. 439).

Sauerwein e Delizoicov (2008) diferenciam a concepção orgânica da concepção denominada de déficit, pois esta última fundamenta-se numa visão ingênua, superficial da realidade. Por meio da concepção de déficit, a prática docente poderá ser consolidada apenas sanando as lacunas apresentadas pelo professor, oriundas de sua formação inicial, sem, entretanto, a imprescindível análise de outras dimensões docentes.

Estes autores evidenciam ainda que a concepção orgânica convive com uma diversa gama de práticas e tendências envolvidas na FCPF. Conforme os mesmos, algumas dessas concepções mantêm um forte vínculo com a concepção do déficit.

\subsection{Algumas PROPOSTAS didÁtiCAS NA FORMAÇÃo CONTINUADA DE PROFESSORES DE}

\section{FíSICA PARA O ENSINO DE ASTRONOMIA}


A seguir serão apresentadas algumas propostas didáticas para a formação continuada de professores no ensino de Astronomia, tendo ênfase na utilização de um Planetário. É interessante que se tenha uma atenção especial quantos aos aspectos que nortearam a construção dessas propostas.

Leite (2006, p. 74-75) esclarece sobre os critérios adotados na escolha das atividades no curso de formação realizado pela mesma:

Reconhecendo o papel da mudança de referencial e da proporcionalidade para a aprendizagem da Astronomia no nível fundamental de ensino foi elaborado um curso de formação continuada para professores de Ciências, no qual priorizamos atividades e discussões que de alguma forma estimulassem a construção da espacialidade, contribuindo para uma maior mobilidade nas mudanças de referenciais e, também, nesta mesma perspectiva, inserimos atividades de proporções, sejam de tamanho, distância, forma ou tempo, de maneira a promover o desenvolvimento de noções espaciais na Astronomia, promovendo necessárias articulações entre o todo e a parte (LEITE, 2006, p. 74-75).

Quanto aos conteúdos escolhidos, a autora argumenta que:

[...] são aqueles mais presentes no ensino fundamental e também indicados nos PCN's, ou seja, os atores principais que compõem o Sistema Solar: Sol, Terra, Lua e demais planetas; além dos fenômenos comuns em nosso cotidiano: dia e noite, estações do ano, fases da Lua e eclipses. Muitas das atividades utilizadas no desenvolvimento da proposta já constam de bibliografia da área, entretanto elas foram reelaboradas e rearticuladas para o nosso propósito (LEITE, 2006, p. 75).

Costa, Euzébio e Damasio (2016) relatam a importância da inserção dos temas "História da Astronomia" e "História e Filosofia da Ciência" na formação inicial de professores:

A formação inicial docente foi implementada a partir da História da Astronomia, ou seja, do caminho percorrido ao longo dos anos que contribuiu para o arcabouço de conhecimento. Assim, no início os temas que envolveram a contribuição de filósofos e cientistas foram tratados de forma ao inserir a História e a Filosofia das Ciências na exposição, demonstrando que a Ciência não é algo linear e a forma que o conhecimento científico foi construído.

A inserção da História e Filosofia da Ciência é algo que facilita o entendimento das relações entre Ciência e Sociedade, sendo relevante no ensino de Ciências da Natureza [...] (p. 73).

No que se refere à relevância quanto ao uso do Planetário na formação de professores,

Leite (2006, p. 93) discorre que:

\begin{abstract}
Atividades de ampliação do Universo para além do Sistema Solar também foram incorporadas a nossa proposta. Para isso, realizamos uma visita ao planetário da Estação Ciência e um estudo das potencialidades de um programa de computador, o software Skyglobe. Os motivos essenciais para a inclusão destas atividades foram, em primeiro lugar, a dificuldade de observação do céu nas grandes cidades e, em segundo, um reconhecimento da grande potencialidade de estudo e conhecimento do céu através desses instrumentos, que possibilitou uma mudança de referencial sem "sair do lugar", mudança essa obtida facilmente numa sessão de planetário, ao mostrar o céu de diferentes latitudes. Além disso, há também a possibilidade de percepção do céu contendo mais do que planetas, Sol e Lua (LEITE, 2006, p. 93).
\end{abstract}


Sobre a realização de cursos de Astronomia para professores, na percepção de Bretones

(2006, p. 27), temos que:

Rompendo-se com a visão de cursos rápidos para professores e de práticas afastadas da realidade dos alunos e da comunidade, é necessário propor outras metodologias de ensino, em Astronomia. Estas metodologias podem levar em conta as demandas sociais, a carência cultural e de informação em muitos campos e formas, com a atuação dos alunos e professores em suas comunidades e até nas famílias. Dessa forma, os participantes podem atuar além da escola, em outros ambientes e situações não escolares, em sua vida de modo geral, atuação essa que gera uma experiência que contribui para sua formação (BRETONES, 2006, p. 27).

Ele complementa ainda:

Espera-se que um programa de formação continuada em Astronomia possa despertar o interesse de professores em obter informações, construindo conhecimento sobre o assunto e sua prática pedagógica. Com essas ações, podem perceber o alcance de suas iniciativas para si mesmos, seus alunos, escola e comunidade. Num programa assim elaborado/planejado os professores teriam acesso a conteúdos acompanhados de técnicas didáticas de construção de modelos ou atividades que possam fazer com seus alunos. Propomos que se aproximem da Astronomia não apenas nas suas salas de aula, mas também na observação dos fenômenos celestes, na leitura dos jornais etc., ou seja, em suas vidas. Isto sim seria uma proposta de formação ou educação permanente. Pode-se dar oportunidades para que falem, troquem experiências e sentimentos (BRETONES, 2006, p. 27-28).

Bretones (2006, p. 104) também se reporta à relevância da utilização do Planetário, quando afirma:

Para o caso da observação do céu fica evidente a necessidade de se trabalhar a prática o que pode ser feito não apenas com mais observações do céu, mas também com o uso de modelos tridimensionais ou até, quando disponível, o auxílio de um planetário (BRETONES, 2006, p. 104).

Quanto ao uso do Planetário na formação inicial dos professores, Costa, Euzébio e Damásio (2016, p. 73) ressaltam que:

A visita ao planetário foi um contribuinte no processo de formação inicial em Astronomia, uma vez que sete alunos afirmaram o quão foi produtiva esta atividade, na qual, nas palavras de A3 “[...] os conceitos que havia visto em sala e tinham ficados vagos, foram reforçados e significados, a partir do momento que conseguiram identificá-los durante a exposição" (COSTA; EUZÉBIO; DAMASIO, 2016, p. 73).

Langhi (2009, p. 126) alerta que:

Os planetários não deveriam funcionar apenas como momentos de lazer ou como rápidas sessões de cultura científica, mas também como parceiros na formação continuada em ensino de astronomia para os professores de ensino fundamental e médio, promovendo cursos, distribuição de materiais didáticos, e o atendimento local e regional, dirigindo-se pessoalmente até as escolas, numa somatória de esforços a nível nacional. Porém, no Brasil, devido à quantidade reduzida destas instituições de divulgação e ensino, a prática destas atividades parece estar distante de nossa realidade, apesar de alguns dos nossos planetários promoverem excelentes trabalhos locais, mas, sobretudo, pontuais. 
Iachel e Nardi (2013) inferem haver um consenso acerca da importância dos espaços não formais de ensino de Astronomia, como planetários e observatórios, a fim de apoiar pedagógica e instrumentalmente os professores em formação e atuação. Os autores indicam a criação de centros de referência pelo país, vislumbrando amenizar as deficiências na formação de professores.

Na pesquisa de Barai et al. (2016) sobre Astronomia nos anos iniciais do Ensino Fundamental, em que foi realizado um curso de aperfeiçoamento para professores, reconheceuse a relevância da parceria entre universidade e escola.

Com certeza, o estreitamento da distância escola e universidade, possibilitando o trabalho em conjunto e promovendo ações de aprendizagem para ambos, pode ter um papel fundamental para que possamos elevar o nível de ensino do nosso Brasil em todas as suas fases, desde o infantil ao superior (BARAI et al., 2016, p. 1022).

Sabe-se sobre a importância das universidades para um país, na formação de profissionais mais preparados para o exercício de suas funções na sociedade. Para que elas alcancem esse objetivo, entre outros, as mesmas se fundamentam em três eixos, a saber: ensino, pesquisa e extensão.

Presume-se que esses eixos não devem ser trabalhados de forma isolada, desconectada. $\mathrm{Na}$ verdade, devem complementar-se, seja para o desenvolvimento científico e tecnológico do país, assim como para a formação de professores. A Universidade precisa oportunizar aos futuros docentes a assimilação de saberes e competências que serão essenciais para o seu trabalho pedagógico.

Admite-se que os saberes docentes influenciam diretamente na prática pedagógica dos professores. Portanto, cabe à Universidade ressignificar e reformular, de forma permanente, sua proposta curricular, assim como suas atividades, parcerias e divulgações. Caso contrário, seu papel social estará comprometido.

Quanto aos saberes pedagógicos mobilizados por esses profissionais, especialmente na utilização de um Planetário como recurso metodológico para o ensino de Astronomia, é preciso, inicialmente, realizar um estudo sobre o tema.

Posto isso, Langhi (2009) destaca alguns dos saberes docentes que devem ser mobilizados pelos professores no seu trabalho pedagógico:

- Saberes dos conteúdos a serem ensinados;

- Saberes dos conteúdos pedagógicos;

- Saberes didáticos dos conteúdos a serem ensinados;

- Saberes curriculares; 
- Saberes dos contextos;

- Saberes culturais;

- Saberes sobre os alunos;

- Saberes pessoais;

- Saberes pré-profissionais;

- Saberes experienciais da profissão docente;

- Saberes profissionais gerais;

- Saberes competenciais.

\section{Resultados}

Os Parâmetros Curriculares Nacionais para o Ensino Médio - PCNEM (BRASIL, 2000) estabelecem que as tecnologias sejam implementadas de forma efetiva no processo de ensinoaprendizagem. Todavia, infelizmente, as mesmas não foram exploradas significativamente no ensino de ciências (DAMASCENO, 2016).

As escolas públicas apresentam ainda uma remota utilização dos recursos tecnológicos pelos professores, tanto por uma formação inicial inadequada quanto pela falta de tempo para preparar atividades diferenciadas (BRETONES, 2006; LEITE, 2006; GUIDOTTI, 2014).

O Planetário classifica-se como um ambiente não-formal de aprendizagem, pois este local proporciona situações não vividas nas escolas (FALK; STORKSDIECK, 2005). Braund e Reiss (2006) destacam a contribuição destes ambientes na elaboração de um melhor currículo de ciências, indicando que a aprendizagem nesses lugares é mais relevante.

Nesse contexto, orienta-se sempre considerar o conhecimento prévio das crianças, pois isto exercerá influência direta sobre como elas interpretaram novas ideias. Temos, primeiramente, que avaliar as ideias e conhecimentos que as crianças trazem consigo (PLUMER, 2006).

Plumer (2006) desvela que para a assimilação de novas ideias também será necessário desenvolver nos indivíduos certas habilidades: a capacidade de descrever posições e direções, e perceber o movimento quase imperceptível de corpos celestes, entre outras. Essas habilidades devem ser concebidas como pré-requisitos que podem afetar diretamente o que as crianças aprendem e também como podem ser usadas para melhorar as estratégias de ensino.

Plummer (2006) estabelece que um dos maiores desafios no desenvolvimento de um currículo, para favorecer o aprendizado das crianças sobre os movimentos celestes aparentes, é 
determinar que representações dos conceitos são realmente significativos e acessíveis às crianças.

Segundo Barrio (2010), para a compreensão dos conceitos astronômicos, através do uso do Planetário, devem ser realizadas atividades que atendam às diferentes faixas etárias. Também é imprescindível que o professor planeje ações que relacionem diretamente os objetivos escolares com a visita ao Planetário.

Para Plummer (2006), o Planetário permite que os alunos visualizem o movimento de corpos celestes de uma forma que eles seriam incapazes de fazer por conta própria, pois esse instrumento é capaz de projetar mudanças celestes, que normalmente ocorrem em dias, ou até mesmos anos, em questão de minutos.

O Planetário é uma incrível ferramenta a ser usada no ensino de objetos e movimentos no céu a partir de uma perspectiva vista da terra. Ele pode ser utilizado para ajudar os alunos a aprenderem sobre os objetos familiares do dia e da noite. O Planetário cria um ambiente que favorece a aquisição de novos conceitos, por facilitar a conexão com os conhecimentos prévios dos alunos sobre o céu e objetos celestes, fornecendo imagens que imitam o céu real (PLUMMER, 2006).

Contudo, Santana (2017) verificou que muitas visitas aos espaços não formais de ensino, por exemplo, aos Planetários, são tratadas como meros passeios. Percebe-se a inexistência de um planejamento por parte do professor para essas visitações. Geralmente o que é estudado nesses locais não terá continuidade na escola, limita-se somente à visita. Tal fato, segundo a pesquisadora, se deve principalmente à falta de conhecimento metodológico e teórico pelos professores, proveniente de uma má formação básica no ensino de Astronomia.

Assim, concebe-se o Planetário como um relevante recurso teórico e metodológico a ser utilizado na formação continuada de licenciados em Física, devido ao interesse que desperta nas pessoas e visão crítica da realidade, possibilitando que sejam colocados à prova pensamentos de senso comum.

Constatou-se também que as transformações da prática do professor não dependem única e exclusivamente de formações continuadas, e sim de outras dimensões relevantes da tarefa docente, tais como: a organização escolar, a relevância dada à formação continuada e permanente dos professores por suas unidades escolares, apropriação de pesquisas em ensino de Física no planejamento das aulas, entre outras. 


\section{CONSIDERAÇões FINAIS}

Portanto, constatou-se que a formação de professores de ciências no Brasil ainda apresenta muitas dificuldades. São encontrados em diferentes trabalhos que um número expressivo de futuros professores deixa seus cursos de graduação, até mesmo de formação continuada, apresentando graves deficiências, inúmeras lacunas.

Verificou-se que, em nosso país, poucos são os cursos que oferecem a disciplina de Astronomia, sendo que estes quando presentes são ofertados de forma optativa/eletiva. Notouse também que o conteúdo abordado na grande maioria dos cursos ainda é bem tradicional, em outras palavras, resume-se normalmente ao estudo de conceitos desconectados com a realidade dos alunos e que oportunizam poucas atividades práticas, sobretudo de observações do céu, utilizando ou não instrumentos de observação.

Notou-se também que muitos professores e alunos apresentam um número significativo de concepções alternativas, que resistem ao passar dos anos, até mesmo por toda a Educação Básica. Estas representam sérios obstáculos epistemológicos a serem superados.

Agravando ainda mais esse quadro, são encontrados poucos materiais adequados aos professores e alunos como fonte de pesquisa. Nota-se que, quase sempre, a fonte de dados de boa parte dos professores brasileiros limita-se aos livros didáticos, onde são verificados muito erros conceituais.

Defende-se que o Planetário pode proporcionar ao professor licenciado em Física uma fundamentação de abordagem teórica e metodológica, para uma mudança de postura em sua prática pedagógica, a fim de preencher lacunas que comprometem o seu trabalho pedagógico. Caso isso não ocorra, muito provavelmente, as visitas ao Planetário serão baseadas no senso comum.

Acredita-se também que a criação de centros de referência de ciências no Brasil poderá atenuar as deficiências na formação de professores de Física para ensinar a disciplina de Astronomia.

Infere-se também que as transformações da prática do professor dependem de diferentes dimensões relevantes da tarefa docente, como, por exemplo, da organização escolar, da relevância dada à formação continuada e permanente dos professores por suas unidades escolares, da apropriação de pesquisas em ensino de Física no planejamento das aulas, das dificuldades dos professores da tarefa docente, das concepções do professor, especialmente, sobre o papel da educação e do ensino de Física, entre outras. 


\section{REFERÊNCIAS}

BARAI, Alexandre et al. Astronomia nos anos iniciais do Ensino Fundamental: uma parceria entre universidade e escola. Caderno Brasileiro de Ensino de Física, v. 33, n. 3, p. 10091025, 2016.

BARRIO, Juan Bernardino Marques. El planetário: um recurso didáctico para la enseñanza de la astronomia. 2002. Tese (Tesis Doctoral) - Universidad de Valladoid, Facultad de Educación y Trabajo Social, Departamento de Didáctica de las Ciencias Experimentales y Geodinâmica, Valladoid, 2002.

BARRIO, Juan Bernardino Marques. A investigação educativa em astronomia: os planetários como espaços de ensino e aprendizagem. In: LONGHINI, M. D. (Org.) Educação em astronomia: experiências e contribuições. Campinas: Átomo, 2010. p. 159-178.

BISHOP, Jeanne E. The educational value of the planetarium. Planetarian, v. 8, p. 1-6, 1979. BRASIL, Ministério da Educação. Secretaria de Ensino Básico. Parâmetros Curriculares Nacionais Ensino Médio. Brasília. MEC/SEB, 2000. 109 p.

BRAUND, Martin.; REISS, Michael. Towards a more authentic science curriculum: the contribution of out-of-school learning. International Journal of Science Education, v. 28, n.12, p.1373-1388, Out. 2006.

BRETONES, Paulo Sergio. A Astronomia na formação continuada de professores e o papel da racionalidade prática para o tema da observação do céu. Tese de doutorado. Programa de Pós Graduação em Ensino e História de Ciências da Terra. Universidade Estadual de Campinas. 252 pp. 2006.

COSTA, Samuel; EUZÉBIO, Gleison João; DAMASIO, Felipe. A Astronomia na formação inicial de professores de ciências. Revista Latino-Americana de Educação em Astronomia - RELEA, n. 22, p. 59-80, 2016.

DAMASCENO, Julio Cesar Gonçalves. O ensino de astronomia como facilitador nos processos de ensino e aprendizado. Dissertação de Mestrado. Programa de Pós-Graduação Mestrado Nacional Profissional de Ensino de Física (MNPEF). Universidade Federal do Rio Grande, Rio Grande, 137 pp. 2016.

DARROZ, Luiz Marcelo; SANTOS, Flávia Maria Teixeira dos. Astronomia: uma proposta para promover a aprendizagem significativa de conceitos básicos de Astronomia na formação de professores em nível médio. Caderno Brasileiro de Ensino de Física, v. 30, n. 1, p. 104130, 2013.

FALK, John Howard; STORKSDIECK, Martin. Learning Science from Museums. História, Ciências, Saúde - Manguinhos, v.12 (suplemento), p.117-143, 2005.

GIL, Antônio Carlos. Como elaborar projetos de pesquisa. 4 ed. São Paulo: Atlas, 2008.

GONZATTI, Sonia Elisa Marchi. Um Curso Introdutório à Astronomia para a Formação Inicial de Professores de Ensino Fundamental, em nível médio. Dissertação (Mestrado 
Profissional em Ensino de Física) - Instituto de Física, Universidade Federal do Rio Grande do Sul, Porto Alegre, 2008.

GUIDOTTI, Charles dos Santos. Investigando a inserção das tecnologias na formação inicial dos professores de física nas universidades federais do Rio Grande do Sul. Dissertação de Mestrado. Programa de Pós Graduação em Educação em Ciências. Universidade Federal do Rio Grande. 119 pp. 2014.

IACHEL, Gustavo; NARDI, Roberto. $O$ ensino de astronomia na formação inicial de professores: o imaginário de pesquisadores considerados referências nacionais. In.: Encontro Nacional de Pesquisa em Educação em Ciências, IX, 2013, Águas de Lindóia. Atas do IX ENPEC. Águas de Lindóia: ABRAPEC, 2013, v. 1. P. 1-8.

LANGHI, Rodolfo. Astronomia nos iniciais do ensino fundamental: repensando a formação de professores. Tese de Doutorado. Programa de Pós Graduação em Educação para Ciência. Faculdade de Ciências, Universidade Estadual de São Paulo, Bauru, 370 pp. 2009.

LEITE, Cristina. Formação do professor de ciências em astronomia: uma proposta com enfoque na espacialidade. Tese de Doutorado. Programa de Pós-Graduação em Educação. Faculdade de Educação, Universidade de São Paulo, São Paulo, 274 pp. 2006.

MARIN, Alda Junqueira. Educação Continuada: introdução a uma análise de termos e concepções. Caderno CEDES, v. 19, n. 44, p. 13-20, 1995.

MARTINS, Claudio Souza. O planetário: espaço educativo não-formal qualificando professores da segunda fase do ensino fundamental para o ensino formal. 2009. Dissertação (Mestrado em Educação em Ciências e Matemática) - Universidade Federal de Goiás, Goiânia, 2009.

OTHMAN, Mazlan. Science education in a planetarium. Astronomical Society of Australia. v. 9, n. 1, p. 69-71, 1991.

PLUMMER, Julia Diane.Students' development of astronomy concepts across time. Doctoral Dissertation, The University of Michigan. 2006.

ROBERTO JUNIOR, Artur Justiniano; REIS, Thiago Henrique.; GERMINARO, Daniel dos Reis. Disciplinas e professores de Astronomia nos cursos de licenciatura em Física das universidades brasileiras. Revista Latino-Americana de Educação em Astronomia RELEA, n. 18, p. 89-101, 2014.

ROMANZINI, Juliana. Construção de uma sessão de cúpula para o ensino de Física em um Planetário. Dissertação de Mestrado. Programa de Pós-Graduação em Ensino de Ciências e Educação Matemática. Mestrado em Ensino de Física. Universidade Estadual de Londrina, Instituto de Física, Londrina. 171 pp. 2011.

SALVI; Rosana Figueiredo; BATISTA, Irinéa de Lourdes. Perspectiva pós-moderna e interdisciplinaridade educativa: pensamento complexo e reconciliação integrativa. Ensaio, v. 8, n. 2, p. 147-160, 2006. 
SANTANA, Agatha Ribeiro. Concepções dos professores sobre a utilização dos espaços não formais para o ensino de Astronomia. Dissertação de Mestrado. Universidade Estadual Paulista. Faculdade de Ciências, Bauru, 2017.

SAUERWEIN, Inés Prieto Schmidt; DELIZOICOV, Demétrio. Formação continuada de professores de Física do ensino médio: Concepções de formadores. Caderno Brasileiro de Ensino de Física, v. 25, n.3, p. 439-477, 2008.

SAUERWEIN, Inés Prieto Schmidt; DELIZOICOV, Demétrio. Desafios da formação continuada de professores de Física. ENCONTRO NACIONAL DE PESQUISA EM EDUCAÇÃO EM CIÊNCIAS, 7, Florianópolis. Anais... Florianópolis: ENPEC, 2009.

THORNBURGH, William Raymond. The role of the planetarium in students' attitudes, learning, and thinking about astronomical concepts (2017). Electronic Theses and Dissertations. Paper 2684. Disponível em: <https://doi.org/10.18297/etd/2684>. Acesso em: 05 jun. 2018.

Recebido em: 05 de março de 2019.

Aprovado em: 18 de maio de 2019. 